\title{
Can a Developed Structure be Transparent? The Analysis of Witcher 3: Wild Hunt Interface with Regard to its Influence on the Player's Immersion
}

\section{Katarzyna Gozdowska}

\begin{abstract}
In this article I analyze the interface of The Witcher 3: Wild Hunt with regard to its transparency as well as its influence on the player's immersion. Furthermore, I scrutinize all measures used by the interface to decrease the effect of emersion, which might appear as game information is being read by the player. I also consider the literary context in my research - I reflect on how the interface refers to Andrzej Sapkowski's Witcher cycle and how these references have been implemented in the interface structure.
\end{abstract}

Keywords: witcher, interface, immersion, emersion, Andrzej Sapkowski 



\section{Interface determinants}

Jon Dovey and Helen Kennedy made an interesting observation about the interface: they compared it to the tissue connecting the player's body with the machine (2011, p. 136). This almost biological metaphor may seem exaggerated at first, but after looking at the essence of the interface it transpires to be accurate. The interface performs a communication function (it constantly provides the player with information about what is happening in the game world) as well as a tool function (the user can use it to make interactive actions in the game) (Kubiński, 2016, p. 25). Kristine Jørgensen also perceives the interface to be an intermediary layer in the interaction between the user and the game system, although it should be mentioned that, according to the author, it does not only consists of a $2 \mathrm{D}$ screen overlay. According to Jørgensen, the interface includes all the elements ensuring the exchange of information between the user and the system, therefore, also the diegetic ones (although the author does not define them with such a term). The researcher considers the functionality and the effective communication between the player and the game as the most important interface features (2013, pp. 20-21). Alexander R. Galloway shares this belief, although he does not see $\mathrm{UI}^{1}$ only as a layer - according to this author, interfaces "are autonomous spheres of activity. Not things, but rather processes that produce various effects". Simultaneously, he sees UI as an entity full of contradictions: on the one hand, it should be intuitive and transparent enough not to draw too much attention to itself, yet on the other, it cannot be too neutral, lest it would completely disappear and lose its intermediary status (Galloway, 2015). It is worth emphasizing that maintaining this status proves to be significant, especially from the player's point of view; satisfying gameplay may only occur if the user is aware of playing the game - performing activities whose main purpose is fun. A complete disappearance of the interface could therefore deprive the user of the joy of the game (Jørgensen, 2013, p. 35). However, Piotr Kubiński also notes that the operation of the interface can be highly emersive, because it brings out the "intermediated nature of the digital reality stimulated by the game" (2016, p. 26).

\footnotetext{
1 An abbreviation of "user interface".
} 
Dovey and Kennedy noticed, however, that it does not always have to be this way - a properly designed interface that the player can use fluently makes the boundary between the game and reality blurred:

As the player becomes more and more fluent in using the interface and understanding the limitations of the code, he begins to "feel" the game, and controlling its world as separate from the player himself is suspended. Attention is so intense that it suggests that the boundary between the player and machine is disappearing - a situation best represented by cybernetic feedback (Dovey, Kennedy, 2011, pp. 12-13).

Moreover, a skilful use of UI has a significant impact on the player's immersion, as it allows him to feel like an avatar owner (2011, p. 147). According to Erik Fagerholt and Magnus Lorentzon, the interface in extended games should also be extended to allow the player to smoothly obtain all necessary information in order to make the best decisions during the game. The researchers have noted, however, that developers of story-focused games tend to limit the traditional overlay interface that could distort the feeling of "being in the game" in favour of placing information in the diegetic space (2014, pp. 58-59).

These observations provoked me to consider the status of the interface in The Witcher 3: Wild Hunt (hereinafter: $W_{3}$ ) and its transparency. $\mathrm{W}_{3}$ is an extensive cRPG game in which the flow of large amounts of information between the player and the program is extremely important while maintaining the strongest possible impression of immersion. The player expects from games of this genre the best possible connection with the ingame characters. Hence arises an important question about the player's immersion, which is affected by UI, as well as whether the literary prototype plays a big role in the design of the structure and the perception of the interface. Opposing the mechanics and the plot could make my analysis incomplete, as Piotr Sterczewski writes:

\footnotetext{
A textual analysis alone does not provide the tools to examine persuasive measures resulting from game mechanics, while only analysing the mechanics and actions of the player would omit the whole wider discursive context in which they operate (2012, p. 214).
}

However, before I discuss the $\mathrm{W}_{3}$ interface, I will pause to consider the very phenomenon of immersion, which, as Gordon Calleja noticed, was often inconsistently defined by game studies representatives, and too often used interchangeably with the term "presence" (2011, pp. 22-23). According 
to the researcher, one should abandon the voluminous and indefinite term "immersion" in favour of "incorporation" (2011, p. 169). This multidimensional phenomenon consists of several forms of involvement (kinesthetic, spatial, shared, narrative, affective and ludic involvement), the most important of which are the kinesthetic involvement (it is associated with mastering the game, for example, learning the button sequences) and the spatial one (which results from the possibility of exploration and navigating through a virtual environment with the hero). Thanks to the impact of the forms of involvement, the player becomes internalized into the game (2011, pp. 43-44, 170-171). Calleja emphasizes that an important feature of the incorporation is its mutual influence - the player recognizes the game environment as his own, begins to feel almost native, and it absorbs him as an almost inseparable part (2011, p. 169).

I agree with Kubiński, who believes the concept of immersion has taken root in the research tradition too much to be replaced by the term 'incorporation' (2016, p. 49). However, I do not want to completely abandon the research done on the latter phenomenon, as I believe that it may enrich my analysis.

When I write about immersion, however, I will mean the term which has been explained by Kubiński in the following way:

Immersion - the impression of non-mediated participation, direct presence in a computer-generated digital space, resulting, among others, from involvement caused by various factors. The user is absorbed not only by the action presented on the screen (perceived sensually, mainly by sight and hearing), but also by his actions and participation in the game world. The player's activity is crucial here - not only the intellectual one (at the level of interpretation), but also physical, related to the actual impact on the digital world and the actual impact on the course of events. These factors cause the subject to experience immersion temporarily, to a certain extent, to forget about the physical reality surrounding him, undergo the illusion of the non-mediated participation - his senses and intellect are focusing on the digital reality. [...] In its fullest (purely hypothetical) form, this experience would completely absorb our senses and intellect with the impression of full participation in another, digital reality. Simultaneously, limiting the reference of the term "immersion" to "computer-generated space", I emphasize the fact it belongs to digital environments (pp. 51-52).

The researcher emphasizes that the attempt to make this impression determines the final design of the game - developers strive to achieve such an effect among their recipients (Kubiński, p. 53). It is also worth noting that immersion does not have to be associated with realistic, high-quality 
graphics. Although the game world does not have to reflect reality as faithfully as possible, it should be consistent. For the impression of immersion to occur at all, the player must accept the production convention (Filiciak, 2006, pp. 62-63).

Kubiński contrasts immersion with the term "emersion", which he describes as "emerging" from virtual reality. This effect is often used by game developers on purpose - it can be an artistic procedure or introduce additional meaning or quality (2016, pp. 70, 148-150).

\section{The interface of The Witcher 3: Wild Hunt}

The interface of $\mathrm{W}_{3}$ is informative and utilitarian. It shows the player the character's level of vitality, endurance (energy) and toxicity, as well as the number of adrenaline points and experience (information function). The utilitarian aspect of the interface is manifested in the fact that the user can decide which potions, firecrackers or spells his character will use at any given time.

Kubiński claims, "because of its communicative nature, the interface's most important function is its information function" (2016, p. 165). Through it, the player learns about the condition of his hero, he also discovers the world in which he operates. The interface is so universal in many games that it has developed its own symbol system that producers of various genres use (2016, p. 25). In addition, the colours are characteristic, although they "do not have the autonomous power to give meanings, however, very often evoke repetitive meanings" - e.g. the red bar in most games symbolises the hero's life (2016, pp. 178-179).

This pattern was also repeated in $\mathrm{W}_{3}$. The game draws from previous instalments of the series, in which the intense green bar suggested toxicity, while the yellow one - energy (endurance). Therefore, the users who played the previous versions of the game find the interface even more intuitive, because during its creation the conventional colour meanings were used. The icons that appear next to the bars also increase the clarity of the interface. The witcher's Sign is next to the yellow colour, so the user can guess that he should control the level of this field in order to use the spells characteristic of the protagonist's profession. The toxicity strip 
is marked with a skull - the death symbol. It informs the player that if this area is completely filled with green, the game may end in the hero's death (it does not have to, because as the hero develops, the user has the opportunity to buy abilities preventing the witcher's death even after consuming a large amount of potions).

A recognizable code is important to maintain immersion - as the player can quickly absorb the information provided by the system, there is no time to think about the way it is presented. The message is received intuitively, thus the interface itself becomes more transparent. Attention is focused on information, not on the tool that provides it (Jørgensen, 2013, pp. 36-37). The transparency of the interface helps build the impression of nonmediation, which is crucial for the phenomenon of immersion to occur (Kubiński, 2016, p. 59).

Usually, the UI components are not excessively absorbing:

the elements take up little space on the screen, are partially transparent, and the colours are not bright (the red of both the health bar and the button responsible for the interaction is toned down, pale) - all these factors prevent the interface from distracting the player from the presented world (Kubiński, p. 218).

Indeed, such a regularity can be seen in $\mathrm{W}_{3}$. The $2 \mathrm{D}$ interface is characterised by neutral, dark brown and black colours, thus it does not attract too much attention and does not disturb immersion. The only bright colours are the bars of life, strength and toxicity. This can be justified by functionality - owing to such a solution it is easier for the player to notice when the levels of these indicators rise or fall. The legibility of the interface has a positive effect on the feeling of immersion. The user does not have to spend time reading important statistics - just a quick look at the spots that catch the eye with their brightness is enough to know the state of the hero.

The bars located within the interface have a texture. It is best seen in the life bar - since it is the largest. It is covered with a texture reminiscent of human veins. A darker pattern was also embossed there, slightly calming the vividness of the colours. The interface designers thus suggest that the player's avatar is more than a three-dimensional model. The texture is to authenticate the protagonist and raise him to the rank of a person which can be identified with. Therefore, the player should not mindlessly play the game, but play in such a way that his avatar suffers the least 
possible damage and rarely dies. Although the interface is not synonymous with the witcher, it transpires to be not only a tool that helps in navigating the game world, but also the area which actualizes the hero. In order to understand this function better, Galloway's arguments may be recalled. He explains it using the example of ancient poets. For they in their songs have always indicated that they are only conduits for the goddesses of art and science, and these higher entities, through the mouths of the singers, convey their thoughts to the people. Although the poets at the time of creation did not become muses, they were embodied in them thanks to the words they spoke or wrote (2015).

Each of the bars in the upper left corner of the screen is of a different size. The life indicator is the most visible. The ones related to energy, toxicity and adrenaline are smaller, and even smaller is the one showing the experience points. This order is not accidental. The interface should be designed to categorise pieces of information, because the player should know at first glance which of them are more and which are less important (Jørgensen, 2013, p. 39). The life bar is the largest, being the most universal for all styles of play - when life drops to zero, the game will end for every player, regardless of whether their witcher had more alchemical, magical or combat skills. Indicators of toxicity, energy and adrenaline are similar in size and are much smaller than the life bar. They are connected with particular styles of play. The player may develop the character so that he often uses alchemy, while not using the Signs at all. Such a user will monitor the toxicity bar more often than energy. The area dedicated to experience points seems to be the most discreet. In the midst of exciting fights the information about the level of the character is not crucial for the user. They can check the exact number of experience points in the character menu, in which they also decide about the skills that the avatar should use. During duels or while traversing lands, the experience points need not be carefully controlled.

The stylization aspect of the interface plays an important role in eliminating emersion, because it improves the functionality of the medium makes it more transparent and at the same time more communicative (Jørgensen, 2013, p. 40). This can be said when the interface elements match the style of the genre, e.g. in a football game it will be a table presenting the result of the match, such as the one appearing during a televi- 
sion broadcast of the games (Kubiński, 2016, p. 166). This category includes the bar pattern, subdued colours of the interface, as well as a medallion well known from Andrzej Sapkowski's novels. The authors treat this item as an important element of the panel, placing it in the upper left corner of the screen, next to the bars of life, toxicity and endurance. Its appearance is in line with the content of the literary original:

The stranger reached into his jerkin once more and pulled out a round medallion on a silver chain. It pictured the head of a wolf, baring its fangs (Sapkowski, 1993, p. 10).

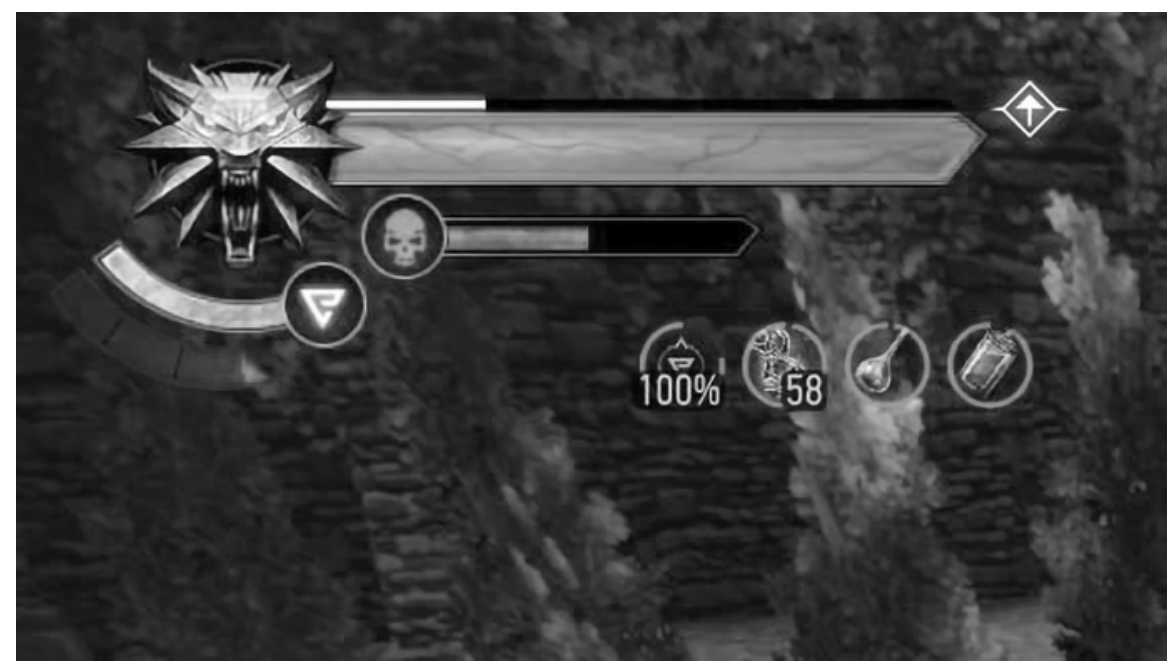

Fig. 1. The medallion's appearance is consistent with the literary description

When threat or magic appears nearby, the medallion vibrates, which means it reacts exactly as it did in Sapkowski's books:

A powerful oscillation of his witcher's medallion warned him of a sudden assault. He jumped aside and, drawing his sword in a flash, deflected and annihilated the violent, paralysing wave of magical energy directed at him with his rune-covered blade (Sapkowski, 1994, p. 237).

The described artefact was an important element of the literary story, so transferring it into the game increases the immersion of the players familiar with the popular Sapkowski cycle. Console users enjoy an 
additional advantage, as when the medallion begins to vibrate, the controller which the user holds in their hands also vibrates. This object turns out to be an element that almost moves beyond the screen space.

The interface in $\mathrm{W}_{3}$ uses little textual information. This is because iconic symbols are easier to read during the game (Celiński, 2010, p. 92); moreover, the text would take up too much screen space:

The use of pictorial symbols is therefore also a manifestation of the ergonomy, desired by players, in the use of screen space (Kubiński, 2016, p. 176).

Analogously, the 2D interface takes up as little space as possible - the game's developers moved some functions to the quick selection menu, which can be activated with the appropriate button, while some information appears in the diegetic space. Thanks to such a solution, the UI designers limited the presentation of information in $2 \mathrm{D}$ to the absolute minimum.

The place of textual information is occupied by much more engaging - from the player's point of view - situational filters and semeions. As explained by Kubiński (2016), the situational filter is an element which does not belong to the diegetic world, visible only on the screen surface. In addition,

In contrast to overlays and metarepresentations, it has the character of an image metaphor, which illustrates the special state of play (thus fulfilling the context filter sub-criterion) (2016, p. 185).

Kubiński defines a semeion as:

Semeion - a diegetic element in the navigable space of the game. It performs the function of a message only from the player's perspective, not on the diegetic level (it does not meet the sub-criterion of the message's diegeticity) (2016, p. 185).

One of the situational filters present in $\mathrm{W}_{3}$ is the blood that appears at the edges of the screen when Geralt is near death. This overlay signals that the hero should take the healing potion or move away from the battlefield for some time to regenerate his health. In case of poisoning with potions, the situational filter is formed by green streaks at the edges of the screen. This is when it is necessary to drink a neutralising toxin mixture. 
Another filter is the one that appears after taking the "Cat" potion. It is worth recalling what happened to the witcher after he had taken the potion:

\begin{abstract}
Geralt flinched a little and swallowed hard. The initial shock of drinking the elixir had passed and the second stage was beginning to take effect, as indicated by a faint but unpleasant dizziness which accompanied the adaptation of his sight to darkness. The adaptation progressed quickly. The deep darkness of the night paled; everything around him started to take on shades of grey, shades which were at first hazy and unclear then increasingly contrasting, distinct and sharp. In the little street leading to the canal bank which, a moment ago, had been as dark as the inside of a tar barrel, Geralt could now make out the rats roaming through the gutters, and sniffing at puddles and gaps in the walls (Sapkowski, 1994, p. 235).
\end{abstract}

The filter accurately reflects the book description. After taking the "Cat", the screens transforms into shades of grey. If the hero is in a very dark environment, everything suddenly becomes perfectly visible, and if he is in a brighter one - the user will be deprived of the comfort of the game, because an overly bright image will hurt his eyes. Therefore, you need an appropriate excuse to take the mixture.

The situational filters help build immersion - the emotional function is more important than the informational one. The player will react more vividly to the view of the bloody border around the screen than to a numerical message showing the value of the hero's injuries (Kubiński, 2016, p. 194), and the users familiar with Sapkowski's books will find the visual references an additional asset that helps to better empathise with the character. Moreover, the overlays and situational filters are a sophisticated way to simulate the avatar's perception (Thon, 2014, p. 87). According to Jan-Noël Thon, the red border symbolising blood is used in games which present a subjective point of view (FPP, i.e. the view from the first person perspective, when the player watches the game world through the eyes of the avatar). Even more interestingly, although in $\mathrm{W}_{3}$ there is a third-person perspective view (TPP; in Thon's classification it will be a semi-subjective point of view), such a filter also occurs here. This may represent the creators' desire to simulate the hero's perception as effectively as possible and is another example of embodying him within the interface.

The semeions appearing in the game, like the situational filters, also refer to Sapkowski's prose. One of them is the change of Geralt's appearance after taking potions. In the original it was described as follows: 
The witcher smiled wryly-he knew what he looked like. After drinking a mixture of banewart, monk's hood and eyebright the face takes on the color of chalk, and the pupils fill the entire iris. But the mixture enables one to see in the deepest darkness (Sapkowski, 1993, p. 27).

In the game, if the level of poisoning of the character is average, slight changes on Geralt's face may be seen - the witcher becomes paler and delicate veins can be seen under his skin. However, when the level turns out to be high, the protagonist's face turns almost white and dark veins appear on his face.

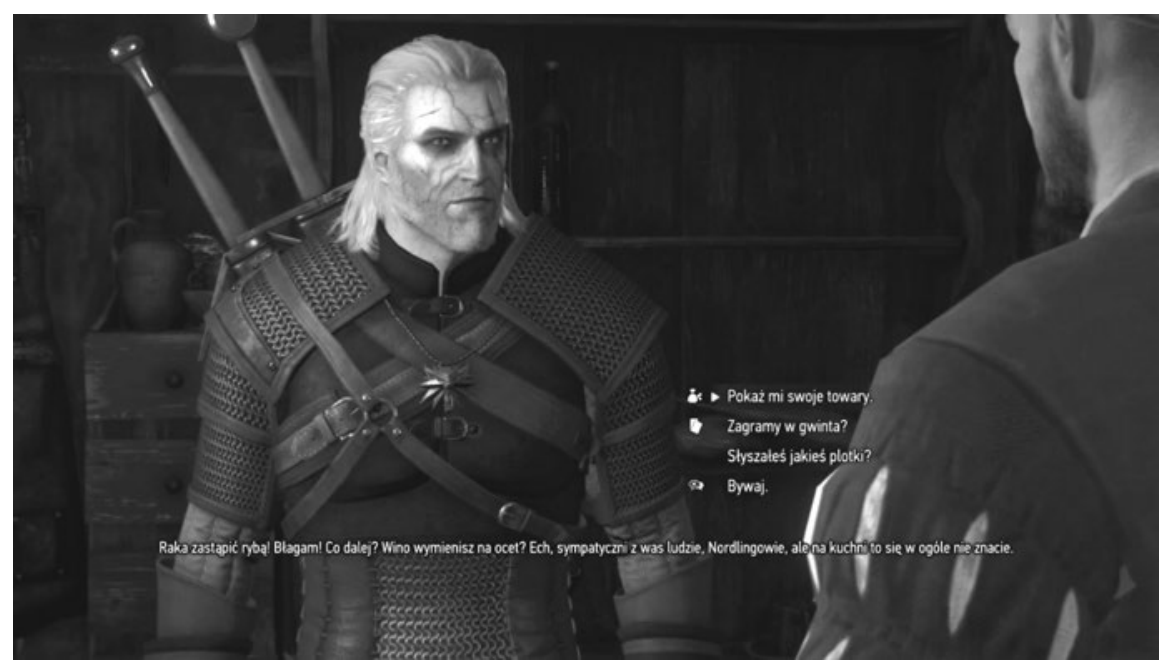

Fig. 2. After drinking too many potions, the witcher's face is covered with visible veins

I think that the beard of the main character, which is becoming more and more lush with time, may also be considered a sort of a semeion. Such qualification of this regularity is debatable - it cannot be said that the others do not notice it, since barber services are available in the game world. Moreover, the main function of this element is to authenticate the world - $\mathrm{W}_{3}$, like the previous parts of the series, strives to involve the user in the game and to make him empathise with the main character (Kubiński, 2015c, p. 114). The main character's beard, however, under certain conditions, may perform an informative function (although it should be remembered that it was not designed for that). There are few places where the barber is available in the game, so on the basis of the growing 
beard, one may determine how many days have passed since the last stay in a village or town with a barber. Of course, the interface also includes a clock showing the time and the part of day, however, during an intense, interesting gameplay, the player may not pay attention to it (or they may turn it off). Then the hero's appearance will make them realise that a lot of time has passed in the game world since he appeared in a given place.

Semeions do not concern the avatar only, but also the means of transport he uses. One of them is the boat, which can be destroyed when an inattentive player rows into protruding rocks or floating crates. The boat may also be damaged by sirens attacking from the air. The air-water monsters sometimes attach themselves to the sides to tear off parts of the boat. The defects in the sheathing allow one to assess the condition of the sailboat, which is impossible to repair, but there is a chance to replace it with another, before it - badly damaged - might simply sink. These visual messages, implemented in the diegetic space to inform about the situation of the hero or the objects in his surroundings, are read more naturally than text messages, thanks to which they deepen the feeling of immersion (Fagerholt, Lorentzon, 2014, p. 60).

The skull icons displayed above the heads of extremely difficult opponents are, in turn, an example of a spatial interface in which "spatial elements are visualised [...] as if they occupied a place in the navigable space of the game" (Kubiński, 2016, p. 202). They let the player know which of the antagonists should be avoided until his hero is developed enough to defeat them. It might seem that these icons have an emersive influence - in addition to the fact that they are not diegetic components, although they are in such an area, they also are not such elements as damage visible on the boat or the changing face of Geralt. They seem unnatural to the diegetic area - they do not fit it stylistically. Jørgensen would probably describe this kind of message as "integrated, ludic and emphatic information", which is a message that appears in the game world (in the diegetic space, although the author avoids this term), even though it does not fit the narration presented by the creators. Such information is used to highlight certain elements of the game world (Jørgensen, pp. 153-154). That is why, in my opinion, the emersive impact of this type of symbol is a contentious issue. The red skull icon informs the player that the opponent in front of them is much more demanding than others, so starting 
a fight might end in the death of the main character. Then a window would appear on the screen announcing the end of the game and the player would have to choose what to do next - exit the game, load the last or even an earlier save. If they decided to keep playing, they would have to wait until the game displays the selected moment, so in the meantime they would have to watch the loading screen. Such a procedure could have a much stronger emersive effect than the red skull icon, thanks to which the player can bypass an excessively difficult opponent and keep playing, developing the character enough to be ready to face the avoided target in the future. The user can also carefully prepare the avatar for battle, making him brew useful potions, repair equipment and anoint the weapon with oil. All these activities contribute to the fortunes of the duel, and thus also to smooth gameplay.

An exclamation mark appears above the heads of some characters who have a task for Geralt to do. This is a common solution:

\footnotetext{
This meaning [the meaning of the spatial UI elements established within a given game] may also be repeated in other games. This applies especially to question marks or exclamation marks - their regular use in the same sense results from the established function of these elements also outside the game: the exclamation mark means something important, the question mark - a secret or simply a question. This is, by the way, another proof that the interfaces are derived from existing cultural codes (Kubiński, 2016, p. 204).
}

Due to the fact that the sign complies with the convention developed by previous games, it does not disturb the immersion as much as a new designation (e.g. a black dot above the head), which the game developers could choose to use. What's more, to compensate for the possible emersion effect caused by the use of a symbol not belonging to the narration, the developers decided to add a sound message. Characters who can activate a side quest often harass the avatar, shouting: "Hey, witcher!" Although it might seem that it would be enough to only use an audio message, it could just turn out to be too subtle, so there would be a risk the player might not notice it. Therefore, the most effective message cannot be too discreet (Jørgensen, 2013, p. 75).

A special solution was used to inform the player about the interactivity of individual elements in the surroundings (Jørgensen, 2013, p. 45). It's about the witcher senses, which are extremely useful during 
investigations in the game. The solution is special because it is on the border of the situational filter and the spatial interface. After pressing an appropriate function key, i.e. after activating a skill, the elements of the environment which can be interacted with are highlighted around the avatar (elements of the spatial interface), and the world itself is slightly blurred. Individual sounds can also be heard more clearly - the sounds of e.g. cities are no longer a cacophony, you can pick up individual conversations or sounds made by objects (elements of the situational filter). At the same time, this solution is transparent because it has a narrative explanation. In the original book, Geralt's skill has no name, but careful tracing of the story shows that the White Wolf can be proud of his extremely meticulous analysis of the environment:

Geralt saw the first corpse immediately - the white of the sheepskin jacket and mattblue of the dress stood out clearly against a yellowing clump of sedge. He didn't see the second corpse but its location was betrayed by three wolves sitting calmly on their haunches [...]. Geralt jumped off his horse.

The woman in the sheepskin and blue dress had no face or throat, and most of her left thigh was gone. The witcher, not leaning over, walked by her.

The man lay with his face to the ground. Geralt didn't turn the body over, seeing that the wolves and birds hadn't been idle. And there was no need to examine the corpse in detail - the shoulders and back of the woollen doublet were covered with thick black rivulets of dried blood. It was clear the man had died from a blow to the neck, and the wolves had only found the body afterward.

On a wide belt next to a short cutlass in a wooden sheath the man wore a leather purse. The witcher tore it off and, item by item, threw the contents on the grass: a tinderbox, a piece of chalk, sealing-wax, a handful of silver coins, a folding shaving-knife with a bone handle, a rabbit's ear, three keys and a talisman with a phallic symbol. Two letters, written on canvas, were damp with rain and dew, smudged beyond readability. The third, written on parchment, was also ruined by damp, but still legible. It was a credit note $[. .$.$] .$

Bending over, Geralt lifted the man's right hand. As he had expected, the copper ring digging into the swollen, blue finger carried the sign of the armorers' guild: a stylized helmet with visor, two crossed swords and the rune "A" engraved beneath them. The witcher returned to the woman's corpse. As he was turning the body over, something pricked him in the finger - a rose, pinned to the dress. [...] He turned the body over completely, and winced.

On the woman's bare and bloody neck were clear bite marks. And not those of a wolf. The witcher carefully backed away to his horse.

"So, Roach," he said quietly, "the case is reasonably clear." The armorer and the woman arrived on horseback from the direction of the forest. They were on their way home from Murivel, because nobody carries an uncashed credit note for long. Why were they going this way and not following the highway? But they were crossing the heath, side by side. And then - again, I don't know why - they both dismounted, or fell from, 
their horses. The armorer died instantly. The woman ran, then fell and died, and whatever attacked her - which didn't leave any tracks - dragged her along the ground, with her throat in its teeth. This happened two or three days ago. The horses ran off. (Sapkowski, 1993, pp. 44-45).

In the case of this solution, an additional audio message appears. As I mentioned, in the game, after pressing the function key, the objects which the avatar can interact with are illuminated. When the interaction happens, the witcher bends over the object (corpse, footprints, paws, wheels, blood, etc.) and makes a comment on it, informing the player how a given piece of circumstantial evidence may be important and what it can mean. Comparing this to the quoted excerpt and Geralt's behaviour in the novels, it may be noted that talking to himself finds an explanation in the literary prototype - after all, Sapkowski also wanted his hero to think aloud.

Although the $\mathrm{W}_{3}$ interface is designed with great care, the game developers have also decided to use the configuration strategy which "partially consists in entrusting the user with the decision on what the interface should look like in the game" (Kubiński, 2016, p. 228).

In the case of $\mathrm{W}_{3}$, it consists in the fact that the player can turn any interface elements off, e.g. of all of its components they can leave only a map, to know what is their movement's direction.

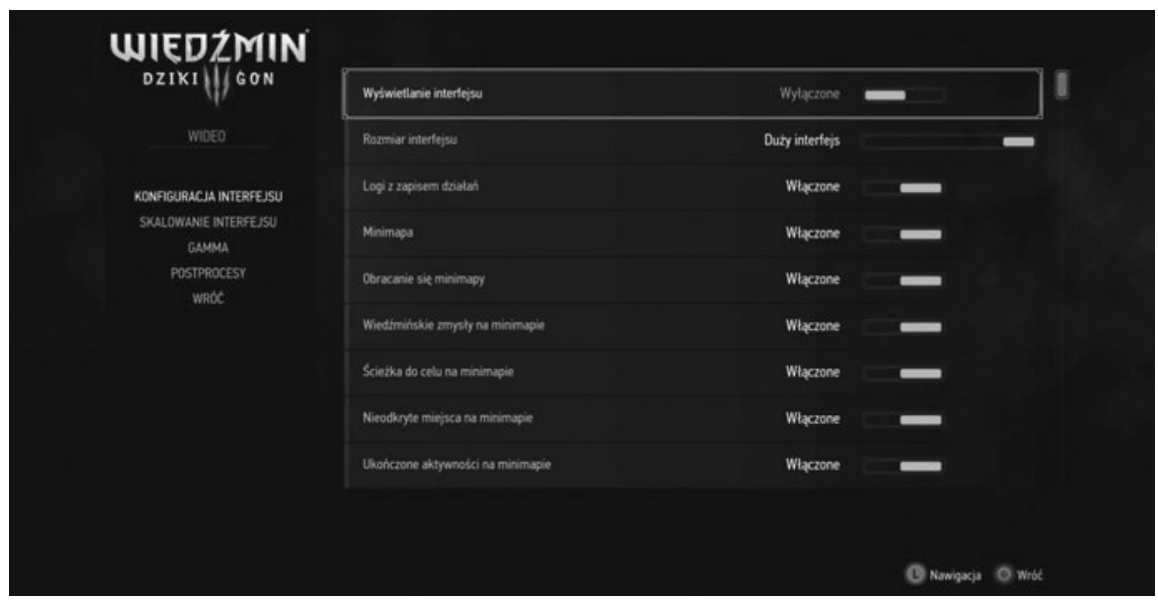

Fig. 3 You do not need to play with the interface enabled

Here, the important role of semeions, the situational filters, overlays and spatial interface is revealed. They provide the player with information 
about the state of the character and the world around him, in spite of the fact that the $2 \mathrm{D}$ interface is invisible. When it is turned off completely, it only contributes to a greater feeling of immersion in some players:

The desire to use the most discreet interface possible is part of the previously described game perception model based on absolutising immersion. The graphical user interface in its simplest form (visible on the screen) is an emersive phenomenon - its very appearance emphasises the mediated nature of the game (Kubiński, 2016, p. 174).

In addition to the information function, the $\mathrm{W}_{3}$ interface also has an impression function which is designed to make the player behave in a specific way at a given moment (Kubiński, 2016, p. 165). When the user guides the hero to the boundaries of the map, the playable area ends and a message is displayed: "Turn back. You've come to the place where the devil says good night” (CD Projekt Red, 2015).

Although this appeal has an emersive impact, it is stylised in such a way as to reduce the impact as much as possible. After all, the content refers to the story The Edge of the World, in which Geralt and Dandillion go to Dol Blathanna, where the witcher is asked to deal with the sylvan ("the devil") Torque. At the end of the song, when Dandillion is thinking about the title for his ballad about the adventures in the Valley of Flowers, the devil becomes an unexpected inspiration for him:

- [...] And I need a title for my ballad. A nice title.

- "Maybe The Edge of the World?"

- "Banal," snorted the poet. "Even if it really is the edge, it's got to be described differently. Metaphorically. [...] Hmm... Let me think... "Where..." Bloody hell. "Where..."

- "Good night," said the devil (Sapkowski, 1993, p. 212).

Informing the player that they should turn back because the playable area is ending may have the effect of emersion, because it refers to Sapkowski's books (and therefore to the world outside the game) or (in the case of users who do not know the original) simply to the Slavic culture which employs the saying: "where the devil says good night" (used to describe places distant from people). Although disturbing the immersion might seem undesirable, the messages are structured so as to reward the player for the feeling of "emerging" from the world of the game. In return for the emersion, the player has the satisfaction of recognising 
the reference and the pleasure that results from the humorous construction of the message (Kubiński, 2015a, pp. 99-100). More importantly, however, such solutions refer to the most important structural element of the Witcher cycle - intertextuality (Kuster, 2015, p. 10). The writer is known for the creative use of conventions and for references to both popular and high culture. Therefore, the interface creators try to reflect the literary inventiveness of the author in the game.

It is also worth mentioning that in addition to seeing the message, the player will hear Geralt saying that he is already too old for such trips. This and the previous examples show that an interface should consist not only of visual but also audio elements if it is to fulfil its informational function (Jørgensen, 2013, p. 23).

The sound is not just made by the character himself. The soundtrack also becomes an event commentator, as well as the UI component. During the duels, the player will hear songs such as Commanding the Fury or Silver for Monsters, which will not be heard during a peaceful journey through lands. While resting at the inn, they will hear The Nightingale, which certainly will not be heard when hunting for monsters. The soundtrack is not only intended to make the game more enjoyable - it also has an informational function. If the player decides to fight and it turns out that the opponent is too strong, they can always run away. Then the soundtrack discreetly suggests whether they are already out of the enemy's reach, because the song from the "battle" will change to the one adapted to the calmer gameplay. The same can occur in the opposite situation: when the player explores the world and suddenly hears a melody that is played only during the fight, they will know that an opponent may be nearby, even if they do not yet see them. The sound, therefore, plays the role of a message, and one that does not disturb immersion. According to Jørgensen, it does not distract the player as much as a visual message - it is more discreet (2013, p. 42).

\section{Summary}

Traditional cRPG games are associated with elaborate interfaces in the form of bars and frames (e.g. Planescape: Torment or Baldur's Gate), which 
ensure the best possible flow of information between the system and the user. $\mathrm{W}_{3}$ is a roleplaying game of a different kind - there is dynamic fighting, not turn-based, conducted in real time. Other interactions between the characters are also dynamic (e.g. dialogues in which time restrictions have been introduced). At the same time, the goal of the game is to allow the user to get the most out of the character. This type of game requires an interface that would provide the player with the information needed to get to know the world and the avatar very well, but which at the same time would not disturb the dynamic aspect of the game.

The interface has to be as transparent as possible, however, it should be noted that the goal is not to eliminate it as much as possible, but to design it in such a way as to make it an integral part of the system, with the main function of being the intermediary without drawing too much attention to itself (Jørgensen, 2013, pp. 25-27).

This effect has been achieved by arranging the $2 \mathrm{D}$ interface and limiting its elements only to the necessary ones. The textual information has been minimised in favour of visual messages, and the particular segments have been put in a hierarchy. The $2 \mathrm{D}$ interface is not distracting because its elements refer to the universe presented in the game, which makes it coherent. Owing to these measures, the user can read the messages quickly and intuitively, focusing on them, not the transmitting medium. The situational filters and overlays prove that the $2 \mathrm{D}$ interface does not have to only present information - they can also build immersion with their emotional function, and also embody the game hero at the level of the interface.

To make the $2 \mathrm{D}$ interface as economic as possible, some messages were placed in the diegetic space. The semeions have been made transparent through several means. Some of these messages (e.g. the changing appearance of Geralt's face after drinking potions) refer to Sapkowski's prose, which is why the players familiar with the prose not only do not see them as artificial, but also can better relate to the character. The emersiveness of the elements of the spatial interface (e.g. exclamation marks over the heads of the NPCs) has been overcome by adding an audio message spoken by the characters. The soundtrack has also been used to give the player discreet hints.

According to Maria Garda, the transmediary transfer of literature to the sphere of interactive entertainment does not have to consist 
only of recreating the plot (2010, p. 21). This can be seen in the design of the $\mathrm{W}_{3}$ interface structure. Not only icons such as the medallion with the head of a wolf or the messages derived from the stories form the references to Sapkowski's cycle. The game designers also created the elements referring to both the content and the narrative of his cycle (the witcher's senses and how the hero reacts to potions). The most important function of this adaptability is to enable intertextual play with the user and provide them with the pleasure that comes not only from the act of playing, but also from recognising references to the literary prototype hidden in the game (Kubiński, 2015b, p. 39).

The part of the $2 \mathrm{D}$ interface that disturbs immersion the most is textual messages. It is practically impossible to compensate for the emersion effect related to them. Therefore, they are stylised - they refer to popular culture and to Sapkowski's books. As already mentioned, the player feels the pleasure of recognising the hidden references.

Although the game developers have tried to make the interface as transparent as possible, they have also given the users the opportunity to decide on its appearance and allowed turning off the $2 \mathrm{D}$ overlay completely. Simultaneously, they have made sure that the player should receive the information necessary for a satisfying game - thanks to the spatial interface, semeions, as well as the soundtrack and the audio messages.

Therefore, immersion is built by choosing the right means of transfer and communication between the player and the program and by ensuring a consistent structure of the interface (this is not only about visual consistency, but also about whether the interface elements complement each other). The pursuit of total realism in games (reducing the interface to a minimum) could be counterproductive. The consistency of the tool informing the player about the world is more important for creating the impression of "being in the game" (Fagerholt, Lorentzon, 2014, p. 69). Although the interface adopts many book elements, it also uses the conventional ones. The feeling of being present in the game does not necessarily have to be associated with the faithfulness in recreating the represented world. Such faithfulness may intensify the feeling of being in the game, but it is not the key to achieving this effect (Calleja, 2011, p. 21). The W3 interface engages the player on various levels - it helps build ludic and spatial involvement. Users who enjoy learning the rules of the game and 
planning strategies, e.g. duels or character development (ludic involvement [2011, pp. 150-151]), will be satisfied with the ability to read the information displayed in the $2 \mathrm{D}$ interface. Thanks to it, they will find out how much health the avatar will lose to a specific opponent or how many experience points a character needs to advance to the next level. The $2 \mathrm{D}$ interface can also inspire them to set their own goals in the game (e.g. trying to beat a strong opponent without using medicinal potions) and to experiment with the style of the game (e.g. checking which combinations of potions are the most effective and do not cause a drastic increase in toxicity). Players especially fond of discovering new places and exploring the world of the game (spatial involvment) can get even greater pleasure from the game after turning off the minimap ${ }^{2}$, where cities, villages, routes and landforms are marked. Moving around the world can become a challenge for such players.

The $\mathrm{W}_{3}$ interface has retained its intermediary status. Although it is transparent, it is not neutral - it can evoke emotions in the player and quickly provide them with the information they needs. It does not disappear even if the user decides to turn off the $2 \mathrm{D}$ overlay. This is because the interface elements exist in different planes of the game - also outside the presented world. When the $2 \mathrm{D}$ interface does not provide information, messages are transmitted using sound, icons, effects placed in the diegetic space or (in the case of PlayStation 4 and Xbox One) the controller vibration. The $\mathrm{W}_{3}$ interface is a good example of the fact that an extensive structure does not necessarily impose its presence upon the user. Designing on various levels of the game gives good results.

\section{References}

Calleja, G. (2011). In-Game: From Immersion to Incorporation. Cambridge [Massachusetts]: MIT Press.

Celiński, P. (2010). Interfejsy. Cyfrowe technologie w komunikowaniu. Wrocław: Wydawnictwo Uniwersytetu Wrocławskiego.

2 The author is aware of the lack of a detailed discussion of the minimap appearing in the game. This decision stems from the belief that this element deserves a separate description and analysis of the tools W3 developers have used to create space and the means to navigate it. 
Dovey, J., Kennedy, H. W. (2011). Kultura gier komputerowych (tłum. T. Macios, A. Oksiuta). Kraków: Wydawnictwo Uniwersytetu Jagiellońskiego.

Fagerholt, E., Lorentzon, M. (2009). Beyond the HUD User Interfaces for Increased Player Immersion in FPS Games. Göteborg: Chalmers University of Technology.

Filiciak, M. (2006). Wirtualny plac zabaw. Gry sieciowe i przemiany kultury współczesnej. Warszawa: Wydawnictwa Akademickie i Profesjonalne. Galloway, A. (2015). Efekt interfejsu [wstęp] (trans. N. Dubina, M. Paszek, W. Szwebs, B. Szymański, I. Zagdan). Techsty, 10(1). Online: <http:// techsty.art.pl/m1o/a_galloway_efekt_interfejsu.html>. Access date: $30^{\text {th }}$ November 2017.

Garda, MB (2010). Gra "The Witcher" w uniwersum "Wiedźmina". Homo Ludens, 2(1), 19-27. Online: <http://ptbg.org.pl/dl/37/Maria\%2O GARDA\%2O-\%2OGra\%2OThe\%2oWitcher\%2ow\%2ouniwersum\%2O Wied\%C $5 \%$ BAmina.pdf $>$. Access date: $23^{\text {rd }}$ August 2018.

Jørgensen, K. (2013). Gameworld Interfaces. Cambridge [Massachusetts]: MIT Press.

Kubiński, P. (2015a). Dyskurs filozoficzny w grach wideo. Wybrane konteksty w grach „Wiedźmin 3: Dziki Gon”, ,The Stanley Parable” oraz „The Talos Principle". Wielogłos, 25(3), 97-110. Online: <http://www.ejournals.eu/sj/index. php/Wieloglos/article/view/6499/6419>. Access date: $23^{\text {rd }}$ August 2018.

Kubiński, P. (2015b). Co wyczytasz pod skórą „Wiedźmina 3”? Ha!art, 51(3), 35-39. Online: <http://www.ha.art.pl/prezentacje/archiwum-magazynu/4811-co-wyczytasz-pod-skora-wiedzmina-3.html $>$. Access date: $23^{\text {rd }}$ August 2018. Kubiński, P. (2015c). Dystans ironiczny w grach „Wiedźmin” i „Wiedźmin 2: Zabójcy królów". In: R. Dudziński, A. Flamma, K. Kowalczyk, J. Płoszaj (ed.), Wiedźmin - bohater masowej wyobraźni (pp. 113-126). Wrocław: Stowarzyszenie Badaczy Popkultury i Edukacji Popkulturowej „Trickster”. Online: $<$ http://tricksterzy.pl/?wpdmdl=1276>. Access date: $23^{\text {rd }}$ August 2018.

Kubiński, P. (2016). Gry wideo. Zarys poetyki. Kraków: Universitas.

Kuster, M. (2015). Sylwa, palimpsest, intertekst. Modele zapożyczeń intertekstualnych w „Sadze o Wiedźminie”. In: R. Dudziński, A. Flamma, K. Kowalczyk, J. Płoszaj (ed.), Wiedźmin - bohater masowej wyobraźni (pp. 10-19). Wrocław: Stowarzyszenie Badaczy Popkultury i Edukacji Popkulturowej „Trickster”. Online: <http://tricksterzy.pl/?wpdmdl=1276>. Access date: $23^{\text {rd }}$ August 2018. 
Sterczewski, P. (2012). Czytanie gry. O proceduralnej retoryce jako metodzie analizy ideologicznej gier komputerowych. Teksty Drugie, 138(6), 210-228. Online: <http://rcin.org.pl/dlibra/doccontent?id=48357>. Access date: $23^{\text {rd }}$ August 2018.

Thon, J.-N. (2014). Subjectivity across Media: On Transmedial Strategies of Subjective Representation in Contemporary Feature Films, Graphic Novels, and Computer Games. In: M.-L. Ryan, J.-N. Thon (ed.), Storyworlds across Media. Toward a Media-Conscious Narratology (pp. 67-102). Lincoln-London: University of Nebraska Press.

\title{
Cited literary works
}

Sapkowski A. (1993). Ostatnie życzenie. Warszawa: SUPERNOWA.

Sapkowski A. (1994). Krew elfów. Warszawa: SUPERNOWA.

\section{Ludografia}

Wiedźmin 3: Dziki Gon (2015). CD Projekt RED.

Katarzyna Gozdowska, M.A. - a graduate of the Polish Literature and Culture in a European and World Perspective at the Faculty of Polish Studies at the University of Warsaw

\section{Czy rozbudowana struktura może być transparentna? Analiza interfejsu gry Wiedźmin 3: Dziki Gon z uwzględnieniem jego wpływu na immersję gracza}

\begin{abstract}
Abstrakt: W swoim artykule badam interfejs gry Wiedźmin 3: Dziki Gon pod względem jego transparentności, a także wpływu na immersję gracza. Analizuję też zabiegi ukierunkowane na niwelowanie emersji, która może wystąpić, gdy gracz odczytuje informacje prezentowane przez interfejs. W badaniach biorę pod uwagę również kontekst literacki - zastanawiam się, w jaki sposób interfejs nawiązuje do wiedźmińskiego cyklu Andrzeja Sapkowskiego oraz jak owe nawiązania zostały zaimplementowane do struktury interfejsu.
\end{abstract}

Słowa kluczowe: wiedźmin, interfejs, imersja, emersja, Andrzej Sapkowski 